\title{
Psychiatric Symptoms and Psychological Defense Mechanisms in Russian Children and Adolescents with Traumatic Life Experience
}

\author{
Gennady Bannikov ${ }^{1,2}$, Kirill Koshkin ${ }^{1}$, Tatyana Pavlova ${ }^{*}$, Lyudmila Miller ${ }^{2}$, \\ Olga Vikhristiuk' and Larisa Gayazova' \\ 'Center for Emergency Psychological Aid, Moscow State University of Psychology and Education, \\ Moscow - 127051, Russia \\ 2Suicidology Department of Moscow Research Institute of Psychiatry, Federal Medical Research Center for \\ Psychiatry and Narcology, The Ministry of Health of the Russian Federation, Moscow, Russia; \\ darzo@yandex.ru
}

\begin{abstract}
The article describes the results of analyzing the psychological intervention data for children who had experienced a variety of traumatic events: a hostage-taking (Beslan, Russia, 2004), military conflict (South Ossetia, 2008), accidents with fatal cases (Moscow, Russia, 2009-2014) ( $\mathrm{n}=136$ ). Three groups of children and adolescents who had experienced a traumatic event were singled out by the type of their response to the traumatic event, personality features and consequently, the strategies of crisis psychological assistance provided for them. In the structure of Acute Stress Disorder (ASD), three clinical groups with varying syndromes were identified. Clinical picture of the interviewed children and adolescents and the type of psychological intervention used allowed us to suggest the existence of three trauma response mechanisms: regressive, dissociative and introjective. Most adolescents who used regression as a response to the traumatic event showed a reduction of traumatic symptoms. The most unfavorable psychological condition was observed in patients who used dissociation as a response to the traumatic event. The singled out mechanisms of trauma can partially explain the variety of ASD and PTSD clinical forms.
\end{abstract}

Keywords: Crisis, Crisis Psychological Aid, Emergency Psychological Aid, Psychological Defense Mechanisms, Psychological Trauma

\section{Introduction}

Events of mass tragic deaths of children and their families, such as the terrorist attack in Beslan, the hostilities in South Ossetian Tskhinvali, accidents with fatal cases and other traumatic events require providing high quality psychological support to the victims' families and consequently, a revision and clarification of the mental health experts' knowledge about psychological defense mechanisms response to experienced crisis situation and the main strategies for crisis psychological assistance.
The main characteristics of a crisis (traumatic) event are its sudden onset, extreme intensity, duration and severity of the consequences that are above person's adjustment capacities. Crisis state of the survivor or the eye-witness to the accident is characterized by the narrowing and redistribution of the perception:

- Cognitive rigidity associated with stress, anxiety;

- Restructuring of the person's value-semantic sphere;

- Loss of spontaneity and flexibility in behavior, predominance of stereotypy ${ }^{1}$.

\footnotetext{
${ }^{*}$ Author for correspondence
} 
A. G. Ambrumova ${ }^{2}$ defined the crisis state as a "psychological state of a person who has suddenly experienced a subjectively meaningful and severely tolerated psychological trauma (due to the drastic change in the person's lifestyle and world view) or is under the threat of traumatic situation". Understanding the specifics of the emergence and development of the crisis state in every particular case is the basis for developing the crisis psychological assistance strategy.

Characteristics of the worldview of a person who is experiencing a "between life and death" situation were described in detail by N. G. Osukhova ${ }^{3}$.

\subsection{The Image of the Outside World}

The world is perceived as dangerous, threatening, hostile ("intrusive" or "rejecting"). The feelings of loss and catastrophic expectations prevail. The main topics are helplessness, hopelessness, abandonment and repudiation. Consciousness is narrowed and focuses only on the negative aspects of the event, which does not allow the person to perceive event characteristics and life resources that could help change things for the better.

\subsection{The Image of "Self" becomes Negative}

I am "small," "weak," "abandoned," "vulnerable," "defenseless," "superfluous"; I am not able to overcome difficulties and change my life situation for the better.

\subsection{The Image of "Others"}

There is a clear distinction of "other people" for the "close" and "strange" ones, "friends and foes," similar to the archaic opposition "us vs. them."

\subsection{Psychological Time}

The gap in the time continuity is manifested either in nostalgia for the past, combined with the fear of the future or in the "escape into the future" and psychological regression ${ }^{3}$.

Unconscious higher mental processes aimed at protecting the psyche from internal threats and external stressors are called psychological defenses ${ }^{1}$. Different personality types are characterized by using certain types of defenses ${ }^{4}$. According to modern research, the use of certain types of defense mechanisms is inherent in the different types of psychopathology. For example, splitting all-powerful control and primitive idealization are prevalent in patients with border line personality disorder. Mature defense mechanisms are used much less frequently ${ }^{5}$. It is typical for patients with post-traumatic stress disorder to use immature defense mechanisms: avoidance, regression, acting out, projection, suppression and passive aggression ${ }^{6}$. The results of torture and illtreatment victims'examination have shown that the use of mature defenses is associated with less post-traumatic symptoms and of immature ones - with more of them. Contrary to the hypothesis about the effectiveness of primitive defense mechanisms in traumatic situations, the subjects who used denial, undoing and suppression, suffered from more severe post-traumatic symptoms. These results may indicate that the restriction of sensitivity and numbing of feelings in extreme situations reduces the possibility for psychological adaptation to the situation ${ }^{7}$. A study of refugees from North Korea showed that the subjects with PTSD symptoms relied mainly on annihilation and isolation. Other disorders were characterized by the use of other defense mechanisms ${ }^{8}$.

Children are the most vulnerable to a crisis traumatic event ${ }^{9}$. Their psyche is still developing, so the consequences of traumatic events can leave an indelible mark for the rest of their lives. Medical and psychological assistance provided in the early hours and the nearest day after the crisis traumatic event can reduce the likelihood of development of a post-traumatic stress disorder, affective and/or psychosomatic disorders ${ }^{10-14}$.

Accordingly, the primary objective of the research was to study various ASD forms in children and adolescents, depending on the main mechanism of psychological defense.

The objectives of the research included developing strategies for medical and psychological assistance taking into account psychiatric symptoms, personality traits and psychological defense mechanisms of the survivors. Psychiatrists, clinical psychologists and psycho dynamically oriented psychotherapists were involved in the work.

\subsection{The Novelty of the Research}

For the first time a clinical description of acute and chronic psychiatric disorders in children and adolescents, developing as a result of crisis (traumatic) situations, with regard to the leading mechanism of psychological defense was presented and the strategies for the psychological assistance to children and adolescents considering the clinical picture and the mechanisms of its formation were proposed. 


\section{Method}

\subsection{Subjects}

136 children with ACD and PTSD symptoms who had experienced a crisis (traumatic) event and sought medical advice in the early days of the event, after six months and a year : Beslan, Russia - September-November 2004 (after the hostage-taking); South Ossetia - September 2008, June-August 2009 (after the armed conflict), Moscow, Russia (after fatal accidents, 2009-2014). Their mean age was 12.4 years. The age range varied from 7 to 18 years.

\subsection{Procedure}

Crisis psychological assistance, due to various objective reasons, was rendered to the participants irregularly, often with long intervals between sessions. There were two stages of research: crisis psychological aid in the first days after the traumatic event and delayed examination in six months (sometimes in a year) after the traumatic event.

Research methods are clinical and psychopathological.

\subsection{Assessment Instrument}

A clinical scale developed by V. N. Krasnov at the Moscow Research Institute of Psychiatry, taking into account a wide range of psychopathological symptoms of emotional, sensory, somatic and cognitive areas was employed ${ }^{15}$.

\section{Results and Discussion}

In the first days after the traumatic event, all adolescents interviewed had symptoms typical of ASD: a reduced awareness of their surroundings (narrowed consciousness), increased arousal, anxiety, fear, depression, sense of guilt, physiologic reactions, reexperiencing traumatic event (through dreams, games, intrusive distressing memories), sleep disturbance, phobias (nyctophobia, dread of being alone, agoraphobia), derealization, irritability, disobedience, aggression, avoidance (of recollections, conversations, places) and regressive symptoms. However, during an in-depth examination we identified a few structure-forming symptom complexes.

As a result of the clinical assessment of the psychopathological structure of acute stress disorder, we singled out three fundamentally different groups: the first group with the regressive symptoms prevailing, the second group with the dissociative ones. In the ASD structure of the third group, anxious and depressive reactions dominated.

A certain psychological defense mechanism is inherent in each identified group:

- Regression - through a merger with an injury;

- Dissociation- through splitting, extrusion;

- Introjection - through the psychological defense of "turning against oneself."

\subsection{The Crisis Stage of Psychological Aid Rendering}

\subsubsection{The First Group (Regressive Trauma Response Mechanism)}

In the clinical picture of the first group, where regression prevailed (47 persons - 34.5\%), we observed manifestations of helplessness, passivity and increased reactivity to light, sounds and other external stimuli (hypersensitivity), spontaneous emotional reactions, motor agitation, screaming and crying accompanied by intense anger and anxiety related to the traumatic event. It was typical of them to avoid the stimuli associated with the traumatic event constantly, emotional numbness and blocking of emotional reactions that had not been noticed before the trauma. The skills of writing, numeracy and speech worsened in children of primary school age. Enuresis was also recorded. Often, there was observed an increase in the symbiotic relationships with parents, accompanied by the fear of losing them. Making contact with the child, as a rule, was quite difficult due to the child's spatial disorientation.

In general, the clinical picture was characterized by returning to the developmentally earlier way of trauma response, which is characteristic of the regressive mechanism* ${ }^{\star}$ of psychical trauma.

Case 1

A 16-year-old young man who had experienced his mother's death nine days ago sought psychological advice initiated by his father. At that moment he lived with his father, younger sister and maternal grandparents. During the conversation, he was confused and cried. Sometimes, he forced himself to smile. His replies were monosyllable, often he asked to repeat, saying he did not understand or lost the idea of the question. His mood was dominantly 
depressed, anxious. He said that he saw no future, felt abandoned, left behind: "Now, I feel like I am 7 years old". The declined ability of introspection and difficulties in distinguishing sensations, feelings and thoughts were observed, though, according to his father, the young man before the tragedy had been characterized by high sensitivity and ability to self-observation. In addition, according to his father, the teenager did not want to go to school because "he did not understand anything" and did not want to look like an "idiot".

According to McWilliams4, neither a request for support and consolation, nor deliberate seeking out ways of drive discharge, strictly speaking, is not a regression, but just prerequisites for its development. Therefore, following this logic, primary specialist's task at this stage is to prevent further deepening and formation of traumatic regression as such. This is achieved by gradual reflection of the traumatic event and for small children by the methods of play therapy and art therapy. Due to the fact that the feelings necessary for the inner comfort were repressed to the unconscious and manifested themselves as pointless resentment and anger, the main task was to give children the tools to facilitate the expression and understanding of their feelings, the gradual "maturing" through experiencing them. Given that in the state of regression, the victim often demonstrated blurring of interpersonal boundaries through clinging to a significant adult, it was necessary to ensure permanent persistent, but soft distinction between "mine" and "not mine" with systematic verbalization. This practice, combined with psychological education, provided gradual creation of a clear cognitive model of the current situation. The personality's resources necessary for this were given through stabilization techniques - by auto-training. An important aspect of crisis aid for adolescents in this group was the analysis of dreams using screen-techniques. It was possible to regain control of the traumatic experiences gradually. A delayed, controlled discharge allowed getting rid of the excess stress and reducing the regressive tendencies. The main task was to create psychologically safe conditions mostly by the parents' involvement in their children's daily activities which provided recovery of the previous level of the psyche functioning.

Thus, for patients with predominant regressive mechanism of trauma development, the following algorithm was proposed: returning the ability of bodily and sensory observation, restoring the fullness of sensations - affective reintegration - verbalization of the cognitive structure.

\subsubsection{The Second Group (Dissociative Trauma Response Mechanism)}

Psychopathological symptoms were dissociative ones, presented mainly in the form of partial amnesia and conversions. Often the subjects told about the feeling as if the traumatic event was happening again, similar to flashbacks. We noted the repetitive behavior with reacting of the traumatic events. Intense painful emotions caused by internal or external stimuli not connected to the traumatic event were also observed. During the disorganization and demobilization period, we observed a combination of anxiety and irritability, difficulties in interpersonal relationships, reduced memory and attention due to the high level of arousal, increased alertness, hyper vigilance, permanent expectation of a threat. We also recorded paradoxical reactions - euphoria, exaltation, overestimation of one's own capabilities.

Case 2

Two weeks after a traumatic event a mother of a 13-year-old boy consulted the psychologist. According to her, her son suffered fears of uncertain nature, sleep disturbances, aggression and social withdrawal. The teenager was reluctant to talk, the look and facial expressions were tense; his answers were monosyllable. He said that all of a sudden, without any external cause, anxiety, fear, the feeling of cooling arms and numbness on the right side of the face came on him. He suffered from his condition, as he had no control over it. He said his fears had appeared a few days after the tragedy. Talking about it, he was confused in the time sequence of events. He could not remember some "particularly significant moments". He reported that at some point he "like quit feeling", then he felt irritation, anger at what was happening, he started to perceive everything "differently", "as if from outside". Until the moment, he could not "recover", turn back to the "normal condition". Thoughts that he would not be able to cope with the impulsive desire to "physically harm" himself were coming to him with ever increasing frequency.

When dissociation prevails traumatic affect all ways lies in the center of psychological suffering, being contained in a special "bound" state, intolerable and therefore, split off from memory. Providing defense from intense painful feelings and manifesting itself in automatisms, dissociation can lead to social dysfunction. Therefore, 
therapy is successful only in the case of "reconstruction of the traumatic situation in a safe environment and reestablishment of impaired psychodynamic connections with the release of affect"16,17. In this case, the main task is to find a way for the child to express his feelings in a symbolic form. The basic method is a symbolic game. Also the technique called "dissociative regression" was used, which, due to the hypnotic suggestion allowed the patient to move away from the traumatic experience to a certain extent while it was still possible to change the perception of the situation in the patient's mind.

We suggest the following steps for working with patients having the predominant dissociative trauma response mechanism: symbolizing the affect - cognitive restructuring - stabilization of affective-cognitive representation of what has happened - reintegration of displaced feelings and cognitions.

\subsubsection{The Third Group (Introjective Trauma Response Mechanism).}

Case 3

A 14-year-old girl who had lost her 12-year-old younger brother as a result of a tragic event about 1 month ago consulted therapist on her own initiative. During the session she was concentrated and focused, facial expressions were monotonously sad. The speech rate was slowed down a little; she often responded after a pause. Answers were substantial, logical and grammatically correct. She complained of intrusive memories of the tragedy, "I keep seeing my brother, he is before my eyes", "tears come rolling at once", "I feel guilty and angry at myself that I could not save him". She reported that she was tired feeling guilty and inadequate, "living in the past, in the memories". From time to time, feelings of unbearable sadness accompanied by "severe emotional pain" came on her. At this point, she said that she did not want to live, but she understood "the absurdity of the idea", she was trying to endure the pain, "just suffer."

The main targets of psychotherapeutic efforts were over generalization and other cognitive distortions. Taking into account the high level of tension in the body caused by constant self-concentration, we used body-focused techniques: focusing attention on bodily sensations, discussion of postures, gestures, movements, respiration, etc. Identifying hidden ambivalent feelings towards the deceased, such as love and hatred, gaining awareness of them and ability to express them contributed to forming a holistic picture including the whole range of feelings towards the trauma. Only then it became possible to turn the "vicious circle of the nightmare you are stuck in" into the separated from oneself experience, which can be interpreted as "the past experience" and generate "personal meaning" and wisdom.

For this group we proposed the following sequence of steps: correction of cognitive distortions - returning the full spectrum of feelings - integration of the affective sphere - re-introjection of a new picture of a traumatic event.

\subsection{Re-Examination of Survivors}

In a few months (up to 1 year) after the traumatic event, $102(75 \%)$ adolescents were examined, some of them were re-examined. Almost none of them were provided with prolonged psychological assistance. No mental disorders were identified in 25 of them. 77 adolescents demonstrated some psychopathological symptoms: anxio-phobic reactions, psychosomatic and behavioral disturbances, anxio-depressive reactions.

In the first group (the regressive trauma response mechanism), in 5 of 20 adolescents, the regressive symptoms changed for the prevailing anxio-somatized reactions against the background of traumatic alexithymia. Given that the traumatic event had provoked a shift to immature defenses and re-experiencing of traumatic feelings (up to early childhood), intrapersonal conflicts intensified and adversely affected the adolescents' sociopsychological functioning. The aim of the psychological intervention was to increase awareness and management of feelings. Psychologist's role at all stages of the crisis psychological aid was to help the child recognize and control his/her feelings, structure and plan clearly all kinds of social activities.

In the second group (the dissociative trauma response mechanism), 22 of 51 adolescents demonstrated mild anxiophobic reactions, substantially no longer associated with the trauma, symptoms of agitation, not observed before the trauma, difficulties in attention-focusing, increased alertness, hyper vigilance, permanent threat expectation. The adolescents avoided thoughts, feelings, conversations related to the traumatic events, actions, places or people that aroused recollections of the trauma. A year later, partial amnesia regarding traumatic events continued. Such reactions were observed mainly in those children who had needed emergency psychological aid but had 
not received it for the objective reasons (parents had not sought to medical advice of the specialists). For example, when some children were recollecting the traumatic event, an altered state of consciousness developed, characterized by anxiety, confusion of speech, agitation. There was an emotional numbness at recollecting fragments of events ("I was bored"). Aggressiveness and reduced capacity for empathy were probably the most common type of interpersonal difficulties. Some adolescents undergoing the examination admitted that they often felt unmotivated rage attacks, which they "poured out" on their loved ones. Complaints about painful sensations in various parts of the body, problems with breathing and spasms of the larynx prevailed.

As in the acute phase, basic intervention strategy was aimed at gradual return of the alienated feelings (particularly envy, anger), using techniques and methods of art therapy and fairy-tale therapy. Due to the choice of careful methods, children received an opportunity to act out and to gain a wider spectrum of emotional and behavioral responses.

In the clinical picture of the third group (the introjective trauma response mechanism), sub depressive symptoms remained in 7 of 31 adolescents. These symptoms were manifested in symptoms of depression, sense of guilt, intrusive memories of the incident, low self-esteem and a lack of recognition of the trauma consequences. The pathological reaction of grief (depression) as a way to response to the traumatic event was often observed in adolescents with such personality traits as increased responsibility, conscientiousness, perfectionism, rigidity, tendency to stick in traumatic situations. The general strategy of crisis intervention for patients with the introjective mechanism of trauma response was aimed at rethinking and rewriting the narrative of what had happened with realizing the limits of the "omnipotent control" concept. Recognition of one's own restrictions and subsequent integration of these restrictions into the coping strategies allows depriving the sense of guilt, as the main response mechanism, of the power to distort the occurred traumatic events and prevents the identity inflation, which is most often manifested in experiencing the impossibility to fix something, losing the meaning and faith in the future. This was achieved through the creative work with metaphors and symbols focused on the future. Processing of the traumatic experience in various forms of art: plastic arts, collage, graphic arts, enables to put it in an adequate place in the past, releasing the present and future from its toxic burden. Restoring a meaningful perspective for the future, restoring and finding new reasons for existence in the present allow escaping from the swamp of guilt and hopelessness.

Summarizing, we can conclude that, depending on the psychiatric symptoms and leading mechanisms of

Table 1. Symptoms typical of three different psychological trauma response mechanisms

\begin{tabular}{|c|c|c|c|}
\hline $\begin{array}{l}\text { Structural } \\
\text { components }\end{array}$ & Regressive mechanism & Dissociative mechanism & Introjective mechanism \\
\hline Emotional sphere & $\begin{array}{l}\text { Persistent anxiety, apathy, impov- } \\
\text { erishment of emotional reactivity }\end{array}$ & $\begin{array}{l}\text { Predominance of dysphoria and anxio-phobic } \\
\text { reactions }\end{array}$ & $\begin{array}{l}\text { Depression and anxiety } \\
\text { prevails }\end{array}$ \\
\hline Sensory sphere & $\begin{array}{l}\text { Bodily sensations of heaviness, } \\
\text { pressure. }\end{array}$ & $\begin{array}{l}\text { Diverse migrating bodily sensations not } \\
\text { associated with real feelings. Some kind of } \\
\text { sensory alexithymia. }\end{array}$ & $\begin{array}{l}\text { Bodily sensations of pain } \\
\text { and baric nature. }\end{array}$ \\
\hline Vegetative sphere & Not expressed & $\begin{array}{l}\text { Cardiovascular reactions, gastrointestinal } \\
\text { disturbances. }\end{array}$ & $\begin{array}{l}\text { Redness, sweating, gastroin- } \\
\text { testinal disturbances }\end{array}$ \\
\hline Volitional sphere & $\begin{array}{l}\text { Motivation, interests, desires } \\
\text { are weakened due to the lack of } \\
\text { goal-setting differentiation. }\end{array}$ & $\begin{array}{l}\text { Motivation, interests, and desire are focused } \\
\text { onto one's health. The possibility to associate } \\
\text { them with the reality due to the partial or } \\
\text { complete amnesia concerning the traumatic } \\
\text { event is reduced }\end{array}$ & $\begin{array}{l}\text { Motivation, interests, desires } \\
\text { are reduced due to the loss of } \\
\text { feedback of the effectiveness } \\
\text { of one's actions }\end{array}$ \\
\hline Cognitive sphere & $\begin{array}{l}\text { Fixation on the traumatic event, } \\
\text { cognitive-emotional non-differ- } \\
\text { entiation, increased dependence } \\
\text { on significant relatives and } \\
\text { friends, search for support }\end{array}$ & $\begin{array}{l}\text { The accusations of others, self-condemnation, } \\
\text { hypochondriacal ideas, fear of death, deper- } \\
\text { sonalization, derealization, dysmorphophobia }\end{array}$ & $\begin{array}{l}\text { Self-condemnation, the idea } \\
\text { of guilt, Beck's cognitive } \\
\text { triad }\end{array}$ \\
\hline
\end{tabular}


psychological defense, the strategies of crisis psychological aid may be focused on the following:

- In the group with the predominant regressive trauma response mechanism - on acceptance, understanding, compassion and creation of conditions of psychological safety in order to reduce the possibility of further regress.

- In the group with the predominant dissociative trauma response mechanism - on restoring the adaptive forms of defense, reconstructing a traumatic situation in a safe environment and reestablishment of impaired psychodynamic connections with affect release.

- In the group with the predominant introjective trauma response mechanism - on promoting the expression of, response to and rethinking of the traumatic feelings and finding new reasons for existence.

\section{Conclusions}

- In the ASD structure, we identified three clinical groups with varying syndromes depending on the type of a traumatic event response: the first group was characterized by regressive tendencies, the second by dissociative symptoms and in the third group depressive symptoms prevailed.

- Clinical picture of the victims and the type of psychological intervention used allowed suggesting the existence of three psychological trauma response mechanisms: regressive, dissociative and introjective.

- Most victims who used regression as a response to the traumatic event showed reduction of symptoms. The most unfavorable psychological condition was observed in patients who used dissociation as a response to the traumatic event.

- The singled out mechanisms of trauma can partially explain the variety of clinical forms of ASD and PTSD.

- Understanding the trauma pathogenesis through singling out the psychological defenses will offer a more differentiated approach to the choice of strategies and methods of psychotherapy.

\section{Limitations and Perspective}

The work in the conditions of providing emergency psychological aid imposes certain restrictions on the possibility to conduct a scientific research. For example, it seems inappropriate to use questionnaires to assess the survivors' condition, as the therapeutic targets in this case are of higher priority than those of the research, which limits the possibility of using exact statistical methods. Treating victims from other parts of the country involves traveling to the sites, which prevents us from providing prolonged aid to the adolescents and observe the processing of the traumatic event in dynamics.

The intervention approaches for people after traumatic life events, differentiated according to the trauma response mechanisms, proposed in this article, require verification of the effectiveness in further studies using accurate methods to assess changes in the victims' status.

\section{References}

1. American Psychiatric Association. Diagnostic and Statistical Manual of Mental Disorders. 4th ed. Washington, DC: Author; 1994.

2. Ambrumova AG, Poleev AM. Emergency psychological aid in suicide practice: Guidelines. Moscow; 1986. [in Russian].

3. Osukhova NG. Psychological aid in difficult and extreme situations: Textbook for students of higher education institutions. 5th ed. Moscow: Akademiia; 2012. [in Russian].

4. McWilliams N. Psychoanalytic diagnosis: Understanding Personality Structure in the Clinical Process. 2nd ed. Guilford Press; 2011. p. 426.

5. Devens M, Erickson MT. The relationship between defense styles and personality disorders. Journal of Personality Disorders. 1998; 12(1):86-93.

6. Silverstein R. Combat-related trauma as measured by ego developmental indices of defenses and identity achievement. The Journal of Genetic Psychology. 1996 Jun; 157(2):169-79.

7. Punamaki RL, Kanninen K, Qouta S, El-Sarraj E. The role of psychological defenses in moderating between trauma and post-traumatic symptoms among Palestinian men. International Journal of Psychology. 2002 Oct; 37(5):286-96.

8. Jun JY, Lee YJ, Lee SH, Yoo SY, Song J, Kim SJ. Association between defense mechanisms and psychiatric symptoms in North Korean refugees. Comprehensive Psychiatry. 2015 Jan; 56:179-87.

9. Gurwitch RH, Kees M, Becker SM. In the face of tragedy: Placing children's reactions to trauma in a new context. Cognitive and Behavioral Practice. 2002 Aug; 9(4):286-95.

10. Gelkopf M, Berger R. A school-based, teacher-mediated prevention program (ERASE-Stress) for reducing terror-related traumatic reactions in Israeli Youth: A quasi-randomized controlled trial. The Journal of Child Psychology and Psychiatry. 2009 Aug; 50(8):962-971.

11. Sandoval J, Scott AN, Padilla I. Crisis counseling: An overview. Psychology in the Schools. 2009 Mar; 46(3):246-56.

12. Shalev AY, Schreiber S, Galai T. Early psychological re- 
sponses to traumatic injury. Journal of Traumatic Stress. 1993 Oct; 6(4):441-50.

13. Kalmykova ES, Misko EA, Tarabrina NV. Features of psychotherapy of post-traumatic stress. Psychological Journal. 2001; 22(4):70-80. [in Russian].

14. Rybnikov ON, Smekalkina LV. The mechanisms of social and psychological adaptation of people working in hazardous professions in the remote period after exposure to an emergency. The Mechanisms of Stress in Extreme Conditions: Collection of Scientific Publications. Ushakov, I.B. (Editor). Moscow: Istoki; 2004. [in Russian].

15. Krasnov VN. Affective spectrum disorders Moscow: PrakticheskaiaMeditsina; 2011. [in Russian].
16. Cerfolio NE. Multimodal psychoanalytically informed aid work with children traumatized by Chechen war. Journal of the American Academy of Psychoanalysis and Dynamic Psychiatry. 2009; 37(4):587-603.

17. Reshetnikov MM. Mental trauma Monograph. Moscow; 2006. [in Russian].

18. Dmitrieva TB. Clinical psychiatry Moscow: GOETAR: Meditsina; 1998. [in Russian].

19. Kogan BM, Semina TE. The problem of dissociation in psychology and psychiatry. Systemic Psychology and Sociology. 2010; 1(2):43-52. [in Russian]. 